\title{
The Time-Varying Systematic Risk of Carry Trade Strategies
}

\author{
Charlotte Christiansen, Angelo Ranaldo, and Paul Söderlind*
}

\begin{abstract}
We explain the currency carry trade (CT) performance using an asset pricing model in which factor loadings are regime dependent rather than constant. Empirical results show that a typical CT strategy has much higher exposure to the stock market and is mean reverting in regimes of high foreign exchange volatility. The findings are robust to various extensions. Our regime-dependent pricing model provides significantly smaller pricing errors than a traditional model. Thus, the CT performance is better explained by a timevarying systematic risk that increases in volatile markets, suggesting a partial resolution of the uncovered interest parity puzzle.
\end{abstract}

\section{Introduction}

[Engaging in carry trades] is like picking up nickels in front of steamrollers: you have a long run of small gains but eventually get squashed. (“Carry on Speculating," The Economist, Feb. 22, 2007)

A currency carry trade (CT) is defined as borrowing a low-yielding asset and buying a higher-yielding asset denominated in another currency. Although this strategy has proliferated in practice, it is at odds with economic theory. In particular, the uncovered interest parity (UIP) states that there should be an equality of expected returns on otherwise comparable financial assets denominated in

\footnotetext{
*Christiansen, cchristiansen@creates.au.dk, CREATES, School of Economics and Management, Aarhus University, Bartholins Alle 10, 8000 Aarhus C, Denmark; Ranaldo, angelo.ranaldo@snb.ch, Research Department, Swiss National Bank, Börsenstrasse 15, 8022 Zurich, Switzerland; and Söderlind, paul.soderlind@unisg.ch, Swiss Institute for Banking and Finance, University of St. Gallen, Rosenbergstr. 52, 9000 St. Gallen, Switzerland. We thank Antonio Mele, as well as seminar participants at the Arny Ryde Workshop in Financial Economics at Lund University, Swiss National Bank (SNB), Leuven University, and CREATES for comments and suggestions. We are grateful to an anonymous SNB referee, Hendrik Bessembinder (the editor), and Paul Weller (the referee) for constructive comments. Christiansen acknowledges support from CREATES funded by the Danish National Research Foundation and from the Danish Social Science Research Foundation. The views expressed herein are those of the authors and not necessarily those of the SNB. SNB does not accept any responsibility for the contents and opinions expressed in this paper.
} 
2 different currencies. Thus, according to UIP we should expect an appreciation of the low rewarding currency by the same amount as the return differential. However, there is overwhelming empirical evidence against the UIP theory (see, e.g., Burnside, Eichenbaum, and Rebelo (2007) for a recent study).

One of the most plausible explanations for the UIP puzzle and the longlasting CT performance is a time-varying risk premium (Fama (1984)). Relying on this rationale, we analyze whether the systematic risk of a typical CT strategy is time varying and regime dependent.

The literature proposes several explanations for the CT performance, such as exposure to illiquidity spirals (Plantin and Shin (2008)), crash risk (Brunnermeier, Nagel, and Pedersen (2009)), and peso problems (Farhi and Gabaix (2008)), although the latter argument is not supported by the substantial payoff remaining in hedged CT strategies (see Burnside, Eichenbaum, Kleshchelski, and Rebelo (2011)). By applying an asset pricing approach with factor mimicking portfolios, some recent studies relate excess foreign exchange (FX) returns to risk factors (e.g., Lustig, Roussanov, and Verdelhan (2008)).

We propose to account for FX time-varying risk premia by adopting a related but different approach. We apply a multifactor model with explicit factors, where the risk exposures are allowed to change according to one or more state variables. This methodology provides a general framework to explain regime-dependent and nonlinear risk-return payoffs. The investigation of regime-switching models for exchange rates is not new (see Bekaert and Gray (1998), Sarno, Valente, and Leon (2006), and Ichiue and Koyama (2008)). Our contribution is to show that the risk exposure to the stock and bond market in the CT is regime dependent and that regimes are characterized by the level of FX volatility. While there have been other papers that point to the importance of volatility (e.g., Lustig et al. (2008), Menkhoff, Sarno, Schmeling, and Schrimpf (2011)), the present paper is the first to demonstrate that volatility affects exposure to stock market risk.

We use logistic smooth transition regression methodology to explain the systematic risk of CT strategies. In doing so, the state variables have straightforward economic interpretations. More specifically, we model the regimes by adopting proxies commonly used to measure market risk (FX volatility and the Chicago Board of Options Exchange (CBOE) volatility index (VIX)) and either market or funding illiquidity (the bid-ask spread and the TED spread, i.e., the T-bill rate minus the Eurodollar rate). The explanatory financial factors include equity and bond returns. The asset pricing analysis shows that the regime-dependent pricing model provides significantly smaller pricing errors.

Our results on the relevance of the regime dependency of the CT risk shed light on the gamble of currency speculation. By distinguishing between low- and high-risk environments, the danger related to $\mathrm{CT}$ becomes fully visible. In turbulent times, CT significantly increases its systematic risk and the exposure to other risky allocations. This finding warns against the apparent attractiveness of CT depicted by simple performance measures such as the Sharpe ratio. Overall, our contribution can be seen as a partial resolution of the UIP puzzle.

This paper is topical in considering the ongoing financial crisis, which provides a live experiment for many of the ideas that we explore here. 
The structure of the remaining parts of the paper is as follows. Section II outlines the theoretical motivation and our econometric approach, while Section III describes the data. Section IV contains the empirical results. Section V concludes.

\section{Theoretical and Empirical Framework}

\section{A. Theoretical Background}

This paper combines 3 strands of literature to model CT returns. First, traditional factor models for exchange rates (McCurdy and Morgan (1991), Bansal and Dahlquist (2000), and Mark (1988)) suggest that currencies are exposed to equity and bond markets. Second, nonlinear patterns in exchange rate returns can be explained by unwinding CTs and squeezes in funding liquidity (Plantin and Shin (2008)) and limits to speculation hypothesis (Lyons (2001)), as well as the rational inattention mechanism (Bacchetta and van Wincoop (2006)). ${ }^{1}$ These arguments imply that a factor model for exchange rates should allow for different regimes. Third, the recent evidence on market volatility and liquidity risk premia (Acharya and Pedersen (2005), Ang, Hodrick, Xing, and Zhang (2006), and Bhansali (2007)) highlights the need to incorporate the effects of high volatility and liquidity squeezes.

To incorporate and assess these different mechanisms, we model the currency return $(r)$ by a factor model where stock (Standard \& Poor's (S\&P) 500 futures) returns (SP) and bond (T-note futures) returns (TN) are the basic factors,

$$
r=\beta_{\mathrm{SP}}(s) \mathrm{SP}+\beta_{\mathrm{TN}}(s) \mathrm{TN}+\alpha(s)+\varepsilon,
$$

but where the slope coefficients $\left(\beta_{\mathrm{SP}}\right.$ and $\left.\beta_{\mathrm{TN}}\right)$ as well as the "intercept" $(\alpha)$ are allowed to depend on "regime" variables $(s)$ : measures of market volatility and liquidity. We study several proxies for market volatility and liquidity. To account for the autocorrelation that exists in some exchange rates, we also include lags of all variables. In a robustness analysis we replace SP with various Morgan Stanley Capital International (MSCI) world equity indices and also include other regressors like the order flow.

This model has the advantage of being written in terms of traditional risk factors. An alternative is to construct factors from portfolios of exchange rates (Lustig et al. (2008)), which may well give a better fit, but at the cost of making the interpretation of the results more difficult.

\section{B. Econometric Approach}

Our econometric model is as follows: First, let $G\left(s_{t-1}\right)$ be a logistic function that depends on the value of some regime variables in the vector $s_{t-1}$,

$$
G\left(s_{t-1}\right)=\frac{1}{1+\exp \left[-\gamma^{\prime}\left(s_{t-1}-c\right)\right]},
$$

\footnotetext{
${ }^{1}$ Empirical evidence on nonlinear patterns is provided in, for example, Bekaert and Gray (1998), Sarno et al. (2006), Ranaldo and Söderlind (2010), and Ichiue and Koyama (2008).
} 
where the parameter $c$ is the central location and the vector $\gamma$ determines the steepness of the function. Then, our logistic smooth transition regression model (see van Dijk, Teräsvirta, and Franses (2002)) is

$$
r_{t}=\left[1-G\left(s_{t-1}\right)\right] \beta_{1}^{\prime} x_{t}+G\left(s_{t-1}\right) \beta_{2}^{\prime} x_{t}+\varepsilon_{t},
$$

where the dependent variable $r_{t}$ (the CT or currency excess return) is modeled in terms of the set of explanatory variables $x_{t}$ (here, stock returns, bond returns, lags, and a constant) and the regime variable $s_{t-1}$ (in our main case, the lagged FX volatility). The parameters $(\gamma, c)$ are from the logistic function, and $\left(\beta_{1}, \beta_{2}\right)$ are from the regression function.

The effective slope coefficients in equation (3) vary smoothly with the state variables $s_{t-1}$ : from $\beta_{1}$ at low values of $\gamma^{\prime} s_{t-1}$ to $\beta_{2}$ at high values of $\gamma^{\prime} s_{t-1}$. This is illustrated in Figure 1. Clearly, if $\beta_{1}=\beta_{2}$ then we effectively have a linear regression.

\section{FIGURE 1}

\section{Example of Smooth Transition Regression Model}

Figure 1 illustrates the logistic $G(s)$ function in equation (2) used in the smooth transition regression in equation (3)

Effective Coefficient of $x_{t}$ for Different G Functions

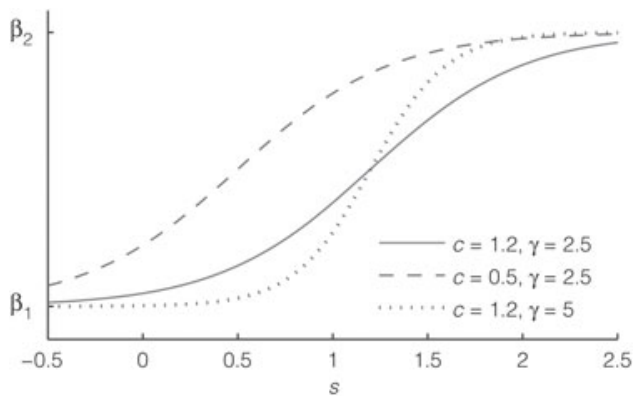

Figure 1 also illustrates how the effective slope coefficient depends on the parameters of the $G\left(s_{t-1}\right)$ function (assuming $s_{t-1}$ is a scalar and $\gamma>0$ ). A lower value of the parameter $c$ shifts the curve to the left, which means that it takes a lower value of $s_{t-1}$ to move from the regime where the effective slope coefficient is $\beta_{1}$ to where it is $\beta_{2}$. In contrast, a higher value of the parameter $\gamma$ increases the slope of the curve, so the transition from $\beta_{1}$ to $\beta_{2}$ is more sensitive to changes in the regime variable $s_{t-1}$.

The model is estimated and tested by using generalized method of moments (GMM), where the moment conditions are set up to replicate nonlinear least squares. Diagnostic tests indicate weak 1st-order (but no 2nd-order) autocorrelation and a fair amount of heteroskedasticity. Therefore, the inference is based on a Newey and West (1987) covariance matrix estimator with a bandwidth of 2 lags.

The explanatory variables are current and 1-day lagged stock and bond returns as well as the 1-day lagged currency return and a constant:

$$
x_{t}=\left\{\mathrm{SP}_{t}, \mathrm{SP}_{t-1}, \mathrm{TN}_{t}, \mathrm{TN}_{t-1}, r_{t-1}, 1\right\} \text {. }
$$


Thus, the regression model in equation (3) is a linear factor model, but where all coefficients can vary according to regime variables. The regime-dependent intercept (alpha) can also be interpreted as the direct effect of the regime on the currency return. ${ }^{2}$

\section{Data Description}

\section{A. Currency Returns}

In our baseline analysis, we investigate the G10 (group of 10 countries) currencies quoted against the U.S. dollar (USD): the Australian dollar (AUD), Canadian dollar (CAD), Swiss franc (CHF), euro/German mark (EUR), British pound (GBP), Japanese yen (JPY), Norwegian krone (NOK), New Zealand dollar (NZD), and Swedish kronor (SEK). The main sample is based upon daily data and runs from January 1995 through December 2008, providing us with 3,653 observations. The starting time is dictated by the availability of data on option-implied FX volatility. In a robustness analysis we include 10 more currencies (G20 (group of 20 countries)) for a shorter sample period covering 2003-2008: the Brazilian real (BRL), Czech koruna (CZK), Israeli shekel (ILS), Indian rupee (INR), Icelandic krona (ISK), Mexican new peso (MXN), Polish new zloty (PLN), Russian Federation rouble (RUB), new Turkish lira (TRY), and South African rand (ZAR). In another robustness analysis we consider a longer sample period, namely 19762008. In this longer sample, only 7 out of the 10 currencies are represented (AUD, CAD, CHF, EUR, GBP, and JPY, all against the USD) due to lack of high-quality data on short-term interest rates.

The daily WM/Reuters closing spot exchange rates are available through Datastream. Following Brunnermeier et al. (2009), we use the exchange rate return in excess of the prediction by UIP (i.e., the abnormal return). Thus, we add the currency return (based on midquotes) and the 1-day lagged interest rate differential between a given country and the United States,

$$
r_{t}^{k}=-\left(q_{t}^{k}-q_{t-1}^{k}\right)+i_{t-1}^{k}-i_{t-1}^{\mathrm{US}},
$$

where $q_{t}^{k}$ is the log exchange rate (the price, in currency $k$, of \$1 USD), $i_{t}$ is the log interest rate for currency $k$, and $i_{t}^{\mathrm{US}}$ is the $\log$ interest rate for the U.S. dollar. We therefore obtain the return on a foreign currency investment in excess of investing on the U.S. money market.

The interest rate data are taken from Datastream, and we use the interest rate with the shortest available maturity, normally the 1-day money market rate (except for Australia and New Zealand, where we use 1-week interest rates).

All individual currency returns have fat tails, these being most pronounced for the AUD. The average returns are negative for typical funding/borrowing currencies $(-3.7 \%$ for JPY and $-1.7 \%$ for $\mathrm{CHF}$, annualized) and positive for some of the typical investment/lending currencies (1.4\% for NZD, annualized).

\footnotetext{
${ }^{2}$ We have also used a smooth transition logistic model where FX volatility is both a regime variable $\left(s_{t-1}\right)$ and an explanatory factor (an element of $x_{t}$ ). The results are similar to those where FX volatility is only used as a regime variable.
} 


\section{B. Carry Trade Returns}

To study typical CT strategies, we rely on the explicit strategy followed by Deutsche Bank's PowerShares DB G10 Currency Harvest Fund. ${ }^{3}$ This is based on the G10 currencies listed in the previous subsection. The CT portfolio is composed of a long position in the 3 currencies associated with the highest interest rates and a short position in the 3 currencies with the lowest interest rates (cf. Gyntelberg and Remolona (2007)). The portfolio is rebalanced every 3 months. We let $r_{t}^{\mathrm{CT}}$ denote the return at time $t$ on the CT strategy.

The weights for the CT portfolio are fairly stable. Usually, the CT strategy is long in the GBP, the NZD, and a 3rd varying currency. It is most often short in the CHF, the JPY, and a 3rd varying currency.

The average CT return is higher than that of any individual currency (4.64\% per year), and the standard deviation is lower than that of any currency except the CAD. This might explain the popularity of the strategy. As in Brunnermeier et al. (2009), we find that the distribution of the return of the CT strategy is left-skewed and fat-tailed.

\section{Additional Variables}

The explanatory variables we use in the empirical analysis represent the 2 other main financial markets, namely the stock and bond markets. To represent the stock market we use the log-returns on the futures contract on the S\&P 500 index traded on the Chicago Mercantile Exchange. The S\&P 500 index is the most tracked equity index worldwide. It is replicated by a number of investment vehicles that are typically liquid and tradable at low transaction costs. Moreover, the use of future data guarantees us a consistent data set during the entire sample period. To represent the bond market we use the futures contract on the 10-year U.S. T-notes traded on the Chicago Board of Trade. The rationale for using the U.S. T-bond is that it is typically considered to be the broadest "safe haven," especially when "flight to quality" and "flight to liquidity" phenomena emerge. Each day we use the most actively traded nearest-to-maturity or cheapest-to-deliver futures contracts, switching to the next-maturity contract 5 days before expiration. We denote these returns at time $t$ by $\mathrm{SP}_{t}$ and $\mathrm{TN}_{t}$, respectively. The futures contracts data are available from Datastream.

To differentiate between regimes, we construct a foreign exchange volatility variable (denoted $\mathrm{FXV}_{t}$ and called $\mathrm{FX}$ volatility). We measure the $\mathrm{FX}$ volatility by the standardized 1st principal component extracted from the most liquid 1-month over-the-counter (OTC) implied volatilities from Reuters (all quoted against the USD): CAD, CHF, EUR, JPY, and GBP. The 1st principal component is close to being an equal-weighted portfolio of the implied volatilities; the weights are $\{0.25,0.20,0.17,0.19,0.19\}$. This measure of FX volatility is particularly high during the period from spring 1995 to spring 1996 (with somewhat lower values during summer 1995) and in early 1998, summer 2006, and late 2008.

\footnotetext{
${ }^{3}$ More information is available on the Deutsche Bank Web site (www.dbfunds.db.com).
} 
In further analysis we use 2 additional stock market proxies, namely the MSCI world index in U.S. dollars including and excluding U.S. stocks. Both indices are recorded in USD. Moreover, we make use of 3 additional regime variables representing market volatility and liquidity. First, we utilize the TED spread, which is the difference between the 3-month USD London Interbank Offered Rate (LIBOR) interbanking market interest rate and the 3-month T-bill rate. Second, we use the CBOE VIX, which is an index of implied volatilities on S\&P 500 stocks. Third, we measure market liquidity with the JPY/USD bid-ask spread computed as the average of the ask price minus the bid price divided by their average at the end of each 5-minute interval during the day. We use the 10-day moving average of the daily bid-ask spreads. We cap the spread at its 95th percentile to eliminate the 10-fold increase on holidays or days with extremely low activity that typically occur between weekends and main holidays like Christmas or New Year's Day.

Finally, we use the order flow for the JPY/USD as an additional explanatory variable. It is defined as the number of buyer-initiated trades minus the number of seller-initiated trades during the day (divided by 10,000). Both the JPY/USD bid-ask spread and the order flow are constructed from firm quotes and trading data obtained by the tick-by-tick data of Electronic Broking Services (EBS). We only have JPY/USD data covering the long sample period from 1997 to 2008. As the JPY/USD is considered to be the exchange rate subject to the most CTs, it provides an interesting proxy. ${ }^{4}$

\section{Empirical Results}

\section{A. Preliminary Results}

The return on the CT strategy is positively correlated with the return on the stock market $(0.19)$ and somewhat negatively correlated with the return on the bond market $(-0.06)$. This means that "investment currencies" like the NZD (the long positions of the CT strategy) tend to appreciate relative to "funding currencies" like the JPY and CHF (the short positions) when the stock market booms. Conversely, investment currencies tend to depreciate against funding currencies when bond prices increase (interest rates decrease). In other words, when the risk appetite of investors decreases and they move to safe assets (e.g., U.S. T-bonds), investment currencies lose value against funding currencies.

While these patterns are already relatively well understood (see, e.g., Bhansali (2007)), it is less well known that the strength of the correlations depends very much on the level of FX volatility and liquidity. As an illustration, column 1 of Table 1 indicates how the correlation between the CT return and the $\mathrm{SP}$ varies across the top quantiles of FX volatility. The figure 0.41 is the correlation between the CT return and the SP return for days when FX volatility is in the top 5\%. The table presents a very clear pattern: The higher the FX volatility, the stronger the correlation between the stock market and the CT strategy. In fact,

\footnotetext{
${ }^{4}$ For more about yen CT, see, for example, Hattori and Shin (2007) and Gagnon and Chaboud (2007).
} 
the correlation coefficients between the stock market and the CT strategy for the 8 top volatility quantiles are significantly higher than the correlation coefficient for the entire sample (GMM-based inference).

TABLE 1

CT Characteristics across FX Volatility Top Quantiles

Table 1 presents the correlation between the carry trade (CT) excess return and the stock return across the top quantiles of FX volatility (FXV) (column 1), the correlation between the CT excess return and the bond return (column 2), the annualized average CT excess return, and the number of observations. The sample period is 1995-2008. Based on a GMM test using Newey and West (1987) standard errors, * and ** indicate that the correlation is significantly different from the full sample (in last line) correlation at the $5 \%$ and $1 \%$ levels, respectively.

\begin{tabular}{|c|c|c|c|c|}
\hline FXV Top Quantile & $\operatorname{Corr}\left(r^{\mathrm{CT}}, \mathrm{SP}\right)$ & $\operatorname{Corr}\left(r^{\mathrm{CT}}, \mathrm{TN}\right)$ & Mean $r^{\mathrm{CT}}$ & No. of Obs. \\
\hline 0.05 & $0.41^{\star \star}$ & -0.19 & -25.35 & 178 \\
\hline 0.15 & $0.33^{\star \star}$ & $-0.13^{*}$ & -14.54 & 535 \\
\hline 0.25 & $0.30^{\star \star}$ & -0.10 & -3.96 & 892 \\
\hline 0.35 & $0.27^{\star \star}$ & -0.09 & -1.36 & 1,248 \\
\hline 0.45 & $0.24^{\star \star}$ & -0.08 & 0.21 & 1,605 \\
\hline 0.55 & $0.23^{\star \star}$ & -0.06 & 1.37 & 1,961 \\
\hline 0.65 & $0.21^{\star}$ & -0.06 & 3.01 & 2,318 \\
\hline 0.75 & $0.21^{*}$ & -0.05 & 2.47 & 2,674 \\
\hline 0.85 & 0.20 & -0.05 & 3.65 & 3,031 \\
\hline 0.95 & 0.19 & -0.06 & 3.71 & 3,388 \\
\hline 1.00 & 0.19 & -0.06 & 4.64 & 3,652 \\
\hline
\end{tabular}

Similarly, column 2 of Table 1 gives the correlations between the CT return and $\mathrm{TN}$ at various top quantiles for the FX volatility. This correlation is negative and numerically stronger for higher FX volatility, although only the correlation coefficient at the 2nd top volatility quantile is significantly stronger than for the entire sample.

These preliminary results suggest that the risk exposures of the CT strategy are much stronger during volatile periods than during calm periods. ${ }^{5}$

Column 3 of Table 1 reports the average returns of the CT strategy for different top quantiles of FX volatility. On average, the CT strategy yields positive and moderately high returns in normal periods, whereas on average it shows dramatic losses during turbulent periods.

\section{B. Carry Trade Strategy}

The preliminary findings suggest that the risk exposure of the CT return is related to the volatility of the FX markets. We now formalize this idea by using a linear factor model (with stocks and bonds as factors), where the betas and the alpha depend on the 1-day lagged FX volatility, according to the logistic smooth transition regression model.

Column 1 of Table 2 gives the base case results from estimating the logistic smooth transition regression model for the CT strategy. The top part of the table presents the parameter estimates applicable for low FX volatility values, denoted $\beta_{1}$ in equation (3), and the middle part of the table presents the parameter estimates applicable for high FX volatility values, denoted $\beta_{2}$. The lower part of the

\footnotetext{
${ }^{5}$ However, the results should be read with appropriate reservations, as Embrechts, McNeil, and Straumann (2002) call for caution when using correlations in risk management.
} 
table presents the difference between the parameter estimates for high and low FX volatility values (i.e., $\hat{\beta}_{2}-\hat{\beta}_{1}$ ). Moreover, the table indicates whether these differences are statistically significant.

\section{TABLE 2}

\section{Smooth Transition Regression with FXV as Regime Variable}

Table 2 presents the parameter estimates arising from estimating the logistic smooth transition regression model on carry trade (CT) excess returns. Columns 1-3 concern the G10 countries (1995-2008), and columns 4-6 concern the G20 countries (2003-2008). The applied equity index varies from the S\&P 500 futures (SP) (columns 1 and 4), MSCI world index including the U.S. (columns 2 and 5), and $\mathrm{MSCl}$ world index excluding the U.S. (columns 3 and 6 ). Based upon Newey and West (1987) standard errors, * and ** indicate that the parameter is significantly different from 0 at the $5 \%$ and $1 \%$ levels, respectively.

\begin{tabular}{|c|c|c|c|c|c|c|}
\hline \multirow[b]{2}{*}{ Coefficients } & \multicolumn{3}{|c|}{$\begin{array}{c}\text { CT on } 10 \text { Currencies } \\
(1995-2008)\end{array}$} & \multicolumn{3}{|c|}{$\begin{array}{c}\text { CT on } 20 \text { Currencies } \\
(2003-2008)\end{array}$} \\
\hline & SP & MSCI World & MSCI World Excl. U.S. & SP & MSCI World & MSCI World Excl. U.S. \\
\hline \multicolumn{7}{|c|}{ Panel A. Regime Function } \\
\hline$\gamma$ & $2.49^{\star \star}$ & $1.82^{* \star}$ & $8.67^{* \star}$ & $7.14^{* *}$ & $7.73^{\star \star}$ & $8.33^{* \star}$ \\
\hline c & $1.25^{\star \star}$ & $1.58^{* *}$ & $2.14^{\star \star}$ & $0.56^{* *}$ & $0.48^{\star *}$ & $0.46^{* *}$ \\
\hline \multicolumn{7}{|c|}{ Panel B. Low Regime } \\
\hline Equity & $0.03^{*}$ & 0.02 & $0.05^{\star *}$ & $0.15^{\star *}$ & $0.22^{\star \star}$ & $0.19^{\star \star}$ \\
\hline Equity $_{t-1}$ & $0.04^{\star *}$ & 0.03 & 0.01 & $0.17^{* *}$ & $0.09^{\star \star}$ & -0.01 \\
\hline & -0.01 & -0.01 & -0.03 & $-0.12^{\star}$ & $-0.11^{\star}$ & $-0.15^{\star \star}$ \\
\hline $\mathrm{TN}_{t-1}$ & -0.03 & -0.02 & $-0.05^{\star \star}$ & -0.05 & $-0.09^{*}$ & $-0.12^{*}$ \\
\hline$z_{t-1}$ & 0.03 & 0.04 & -0.00 & -0.02 & -0.02 & -0.01 \\
\hline$\alpha$ & $0.00^{* *}$ & $0.00^{* *}$ & $0.00^{* *}$ & $0.00^{* *}$ & $0.00^{\star *}$ & $0.00^{* *}$ \\
\hline \multicolumn{7}{|c|}{ Panel C. High Regime } \\
\hline Equity & $0.20^{* *}$ & $0.35^{* *}$ & $0.44^{* *}$ & $0.23^{* *}$ & $0.37^{\star \star}$ & $0.38^{* *}$ \\
\hline Equity $_{t-1}$ & $0.26^{* *}$ & $0.24^{* *}$ & 0.01 & $0.22^{* *}$ & $0.17^{*}$ & 0.03 \\
\hline & -0.20 & -0.13 & -0.20 & $-0.59^{\star \star}$ & $-0.48^{\star \star}$ & $-0.55^{\star \star}$ \\
\hline $\mathrm{TN}_{t-1}$ & -0.13 & -0.19 & -0.14 & $-0.57^{\star}$ & $-0.59^{\star \star}$ & $-0.48^{\star}$ \\
\hline$z_{t-1}$ & $-0.22^{\star \star}$ & $-0.34^{\star \star}$ & -0.13 & $-0.27^{\star \star}$ & $-0.29^{\star \star}$ & -0.21 \\
\hline$\alpha$ & $-0.00^{*}$ & -0.00 & -0.00 & $-0.00^{\star}$ & $-0.00^{\star}$ & $-0.00^{\star \star}$ \\
\hline \multicolumn{7}{|c|}{ Panel D. Regression Statistics } \\
\hline$R^{2}$ & 0.18 & 0.19 & 0.22 & 0.25 & 0.28 & 0.29 \\
\hline No. of obs. & 3,653 & 3,653 & 3,653 & 1,567 & 1,567 & 1,567 \\
\hline \multicolumn{7}{|c|}{ Panel E. High Minus Low Regime } \\
\hline SP & $0.18^{* *}$ & $0.32^{\star *}$ & $0.39^{* *}$ & 0.08 & $0.16^{\star}$ & $0.19^{* \star}$ \\
\hline $\mathrm{SP}_{t-1}$ & $0.22^{\star *}$ & $0.21^{\star *}$ & -0.00 & 0.05 & 0.07 & 0.04 \\
\hline $\mathrm{TN}^{2}$ & -0.20 & -0.12 & -0.17 & $-0.48^{\star}$ & $-0.37^{\star}$ & $-0.39^{\star}$ \\
\hline $\mathrm{TN}_{t-1}$ & -0.11 & -0.17 & -0.09 & $-0.52^{\star}$ & $-0.50^{\star}$ & -0.37 \\
\hline$z_{t-1}$ & $-0.24^{*}$ & $-0.38^{\star \star}$ & -0.12 & $-0.25^{\star \star}$ & $-0.27^{\star}$ & -0.20 \\
\hline$\alpha$ & $-0.00^{*}$ & $-0.00^{\star}$ & -0.00 & $-0.00^{\star \star}$ & $-0.00^{\star}$ & $-0.00^{\star \star}$ \\
\hline
\end{tabular}

The explanatory power of the smooth transition regression model is fairly high: The $R^{2}$ is 0.18 . An ordinary least squares regression gives half of that, which suggests that it is empirically important to account for regime changes in order to describe the exchange rate movements. The estimated value of the $c$ parameter (the central location of the logistic function) is 1.25 , and the estimated $\gamma$ parameter (the steepness) is 2.49 , so the estimated logistic function is similar to the solid curve in Figure 1 discussed previously. The resulting time path of the "regime function" $G(\mathrm{FXV})$ is shown in Graph A of Figure 2. The value is close to 0 most of the time (it is less than 0.1 on $80 \%$ of the days in the sample), and it only occasionally goes above 0.5 ( $6 \%$ of the days). The calm regime (when $\beta_{1}$ is the effective slope coefficient) is thus the normal market situation, while the 
volatile regime (when $\beta_{2}$, or a weighted sum of $\beta_{1}$ and $\beta_{2}$, is the effective slope) represents periods of extreme stress on the FX market.

FIGURE 2

Time Series of Fitted G(FXV) and CT Excess Return

Graph A of Figure 2 shows the fitted G(FXV) function, using the point estimates for the G10 carry trade (CT) strategy in Table 2. Graph B shows the part of the fitted CT return driven by the low state coefficients $\left((1-G) \beta_{1} x_{t}\right)$. Graph $C$ shows the part driven by the high state coefficients $\left(G \beta_{2} X_{t}\right)$. The fitted CT return is the sum of the results in Graphs B and C.

Graph A. Estimated G(FXV)

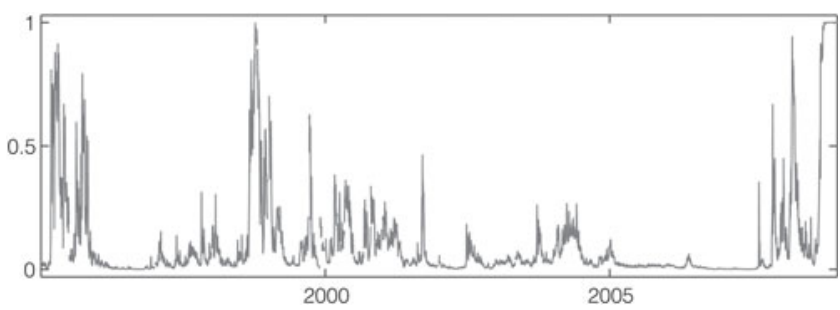

Graph B. Part of Fitted CT Excess Return, $(1-G) \beta_{1} x$

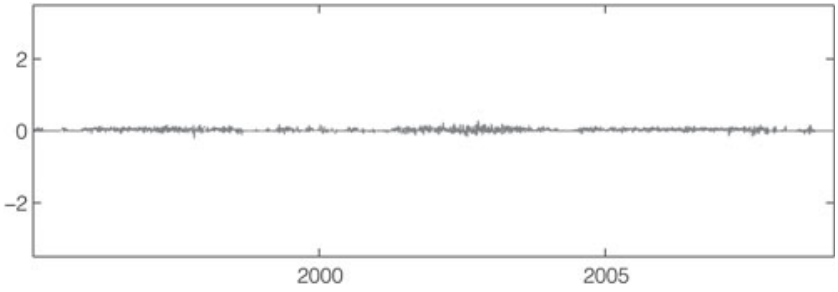

Graph C. Part of Fitted CT Excess Return, $G \beta_{2} x$

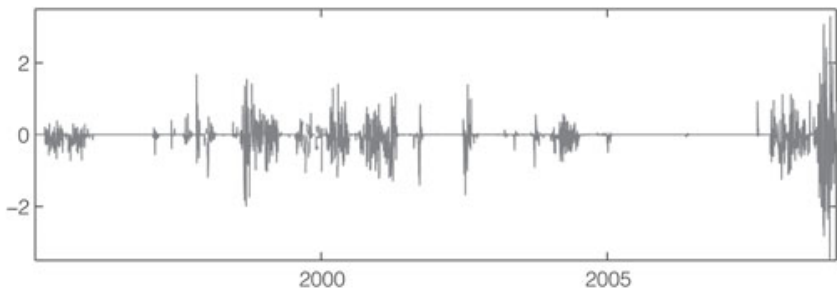

The regression results clearly show that the risk exposure depends on the FX volatility variable. During calm periods, the CT strategy is significantly positively exposed to current and lagged stock returns (although the coefficient is numerically small), but not to the bond market (a numerically small, negative coefficient). During turmoil, the exposure to the current and lagged stock market returns is much larger. The exposure to the bond market also has a more negative coefficient, but the difference between the regimes is not significant. The autoregressive component is small and insignificant during calm periods, but significantly negative during turmoil, which indicates considerable predictability and mean reversion during volatile periods. 
These results are robust to various changes in the empirical specification. First, we get similar results by replacing the SP with either the MSCI world index or the MSCI world index excluding the United States (see columns 2 and 3 of Table 2). In particular, the exposure to equities in the high volatility regime remains very strong. Thus, the CT's exposure to stock market returns appears irrespective of the country of origin of the companies' returns. Moreover, we obtain very similar results when the MSCI indices are in local currencies (results not tabulated). Second, taking into account transaction costs affects the average return of the strategy (decreasing it by 1.12 percentage points per year) but does not change any of the slope coefficients. ${ }^{6}$ The main reason is that the trading costs are fairly stable over time and that there is little rebalancing as the interest rate differentials are very persistent. Third, rebalancing the CT portfolio more/less often than every 3 months does not change the qualitative results. The main reason is that interest rates tend to change smoothly across time and so do portfolio weights. The results are also robust to the number of long and short currency positions in the CT strategy. ${ }^{7}$

To assess the economic importance of the systematic risk of the CT strategy, we consider the fitted values (CT returns) in Figures 2-3. Figure 2 shows the fitted CT returns split up into 2 parts: the 1st part (Graph B) caused by the calm regime $\left((1-G) \hat{\beta}_{1} x_{t}\right)$ and the 2 nd part (Graph $\mathrm{C}$ ) caused by the volatile regime $\left(G \hat{\beta}_{2} x_{t}\right)$. The total fitted CT return adds up to the sum of the 2 parts. Almost all the movement in the fitted CT returns is caused by the volatile regime. So, it is during volatile FX markets that the systematic risk of the CT is most important. This is related to the literature that discusses whether financial market comovement is stronger during financial crises (cf. Forbes and Rigobon (2002), Corsetti, Pericoli, and Sbracia (2005)) and also to the literature on nonlinearities and regime dependence of CT returns (cf. Plantin and Shin (2008), Mark (1988)).

Figure 3 shows the (annualized) fitted returns for different top quantiles of FX volatility. Graph A shows both the actual CT returns (cf. Table 1) and the fitted values from the estimated model: The fit is very good.

Graphs B-D of Figure 3 decompose the fitted values into the contribution from (contemporaneous and lagged) SP returns, TN returns, and alpha (together with the lagged dependent variable). Graphs B-D point in the same direction. The contribution from SP is negative at high FX volatility (around $-6 \%$ ), since the beta of the CT strategy is positive, and SP has, on average, negative returns when FX volatility is high. TN also has a negative contribution $(-4 \%)$ in those states, since the beta is negative and the bond market typically performs well when FX volatility is high. Finally, the combined effect of the alpha and the

\footnotetext{
${ }^{6}$ For each daily return we subtract $1 / 63$ of $1 / 2$ the bid-ask spread from the beginning of the investment period (rebalancing every 3 months) and $1 / 2$ of the bid-ask spread from the end of the period. Since our return data are based on midquotes, the adjusted return is calculated from buying high and selling low. The data used to estimate transaction costs are bid and offered indicative WM/Reuters quotes from Datastream.

${ }^{7}$ Varying the rebalancing frequency between 1 and 6 months (all else being equal) and varying the number of long/short positions between 2 and 4 (all else being equal) gives very similar (i.e., small) coefficients in the low state. For the high state the sum of the contemporaneous and lagged coefficients is between 0.38 and 0.51 for SP and between -0.16 and -0.35 for TN.
} 
FIGURE 3

Fitted CT Returns for Different Top Quantiles of FX Volatility

Graph A of Figure 3 shows how the actual and fitted G10 carry trade (CT) returns (annualized) depend on the FX volatility (FXV). See Table 2 for the point estimates. Graphs B-D decompose the fitted CT return into the parts driven by the S\&P 500 (Graph B), the T-notes (TN) (Graph C), and the combined effect of the "intercept" and lagged CT return (Graph D).

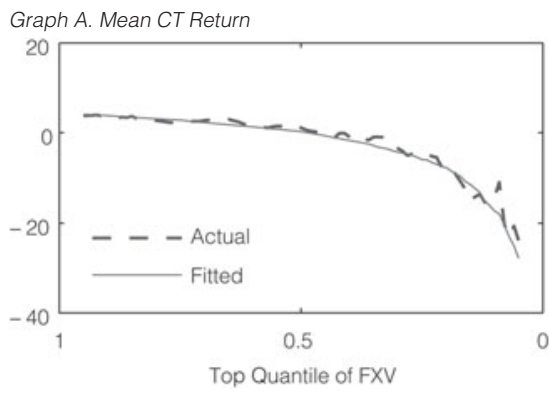

Graph C. Fitted CT Return, TN Contribution

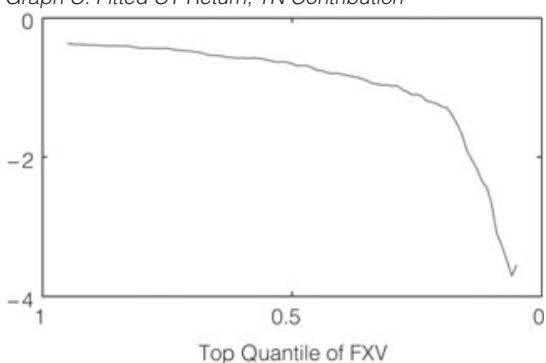

Graph B. Fitted CT Return, S\&P Contribution

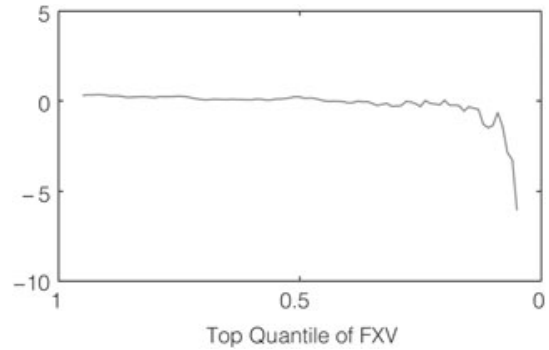

Graph D. Fitted CT Return, $\alpha$, and Lag Contribution

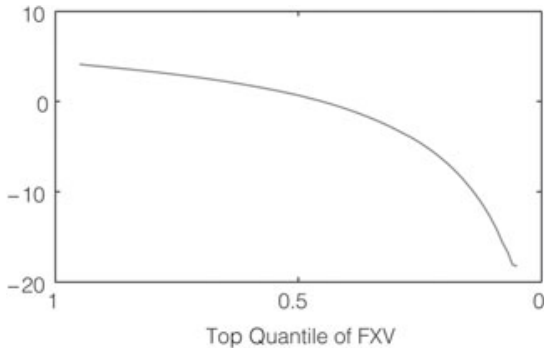

lagged dependent variable is remarkably negative at high FX volatility $(-18 \%)$ but somewhat positive at low FX volatility (5\%). To interpret the latter finding, note that equation (3) shows that the alpha is

$$
\alpha\left(s_{t-1}\right)=\alpha_{1}+G\left(s_{t-1}\right)\left(\alpha_{2}-\alpha_{1}\right) .
$$

Since low volatility (implying $G\left(s_{t-1}\right) \approx 0$ ) is the typical state, we can interpret $\alpha_{1}$ (which is positive) as the typical alpha, and $\alpha_{2}-\alpha_{1}$ (which is negative) as the direct effect of high volatility on the CT return. This is similar to Bhansali (2007) and Menkhoff et al. (2011), who discuss how CTs are negatively affected by market volatility. Note, however, that the alphas should not be taken as literal performance measures, since some of the factors are managed portfolios.

The effect of the lagged dependent variable and the direct FX volatility effect imply a certain amount of predictability (as the state variable is measured in $t-1$ ). We leave this aspect to future research.

To sum up, our results show that around $1 / 3$ of the (disastrous) CT return in the (extreme) high volatility state is accounted for by exposure to traditional risk factors (equities and bonds) and $2 / 3$ by the market volatility factor. This suggests that it is important to model both regime dependence of traditional risk factors (see, e.g., McCurdy and Morgan (1991), Bansal and Dahlquist (2000)) as well as the direct effect of market volatility on CT performance (see, e.g., Bhansali (2007), Lustig et al. (2008), and Menkhoff et al. (2011)). 


\section{Individual Currencies}

Table 3 presents the results from estimating the logistic smooth transition regression model for the individual currency returns. In these regressions, we set $\gamma$ equal to 2.50 to guarantee a unique and consistent number across the panel. The results for the individual currencies are broadly in line with those from the CT. In both regimes, typical investment currencies like the NZD have positive exposure to SP, while typical funding currencies like the CHF and JPY have negative SP risk exposure (a safe haven feature). In most cases, this pattern is even stronger in the high volatility regime (the change in the slope coefficient is significant for all currencies). Together these elements explain why the CT is so strongly exposed to SP risk, particularly in the high volatility regime. In addition, the negative autocorrelation in the $\mathrm{CT}$ strategy in the high volatility regime seems to be driven by the typical investment currencies.

\section{TABLE 3}

Smooth Transition Regression with FXV as Regime Variable

\begin{tabular}{|c|c|c|c|c|c|c|c|c|c|}
\hline Coefficients & AUD & CAD & $\mathrm{CHF}$ & EUR & GBP & JPY & NOK & NZD & SEK \\
\hline \multicolumn{10}{|c|}{ Panel A. Regime Function } \\
\hline $\begin{array}{l}\gamma \\
c\end{array}$ & $\begin{array}{c}{[2.50]} \\
2.24^{\star}\end{array}$ & $\begin{array}{l}{[2.50]} \\
2.28^{\star \star}\end{array}$ & $\begin{array}{l}{[2.50]} \\
2.17^{\star \star}\end{array}$ & $\begin{array}{c}{[2.50]} \\
1.95^{\star *}\end{array}$ & $\begin{array}{c}{[2.50]} \\
1.89^{* *}\end{array}$ & $\begin{array}{c}{[2.50]} \\
1.01^{\star \star}\end{array}$ & $\begin{array}{c}{[2.50]} \\
1.64^{\star \star}\end{array}$ & $\begin{array}{l}{[2.50]} \\
2.26^{\star \star}\end{array}$ & $\begin{array}{c}{[2.50]} \\
1.26^{*}\end{array}$ \\
\hline \multicolumn{10}{|c|}{ Panel B. Low Regime } \\
\hline $\begin{array}{l}\mathrm{SP} \\
\mathrm{SP}_{t-1} \\
\mathrm{TN} \\
\mathrm{TN}_{t-1} \\
\mathrm{Z}_{t-1} \\
\alpha\end{array}$ & $\begin{array}{l}0.03 \\
0.07^{\star \star} \\
-0.00 \\
0.02 \\
0.03 \\
-0.00\end{array}$ & $\begin{array}{l}0.02^{*} \\
0.06^{\star \star} \\
0.01 \\
-0.03 \\
-0.00 \\
0.00\end{array}$ & $\begin{array}{l}-0.08^{\star \star} \\
-0.05^{\star \star} \\
0.23^{\star \star} \\
0.12^{\star \star} \\
-0.03 \\
-0.00\end{array}$ & $\begin{array}{l}-0.06^{\star \star} \\
-0.01 \\
0.18^{\star \star} \\
0.09^{\star \star} \\
-0.00 \\
-0.00\end{array}$ & $\begin{array}{l}-0.03^{\star \star} \\
-0.01 \\
0.11^{\star \star} \\
0.05^{\star} \\
0.02 \\
0.00\end{array}$ & $\begin{array}{c}-0.03^{\star} \\
0.00 \\
0.10^{\star} \\
0.17^{\star \star} \\
0.01 \\
-0.00^{\star}\end{array}$ & $\begin{array}{l}-0.04^{\star \star} \\
0.02 \\
0.14^{\star \star} \\
0.07^{\star} \\
0.05 \\
0.00\end{array}$ & $\begin{array}{l}0.03^{\star} \\
0.06^{\star \star} \\
0.01 \\
0.07^{\star} \\
0.03 \\
0.00\end{array}$ & $\begin{array}{l}-0.03 \\
0.05^{\star \star} \\
0.13^{\star \star} \\
0.13^{\star \star} \\
0.05 \\
0.00\end{array}$ \\
\hline \multicolumn{10}{|c|}{ Panel C. High Regime } \\
\hline $\begin{array}{l}\mathrm{SP} \\
\mathrm{SP}_{t-1} \\
\mathrm{TN} \\
\mathrm{TN}_{t-1} \\
Z_{t-1} \\
\alpha\end{array}$ & $\begin{array}{l}0.27^{\star \star} \\
0.43^{\star \star} \\
0.09 \\
-0.20 \\
-0.34^{\star} \\
-0.00\end{array}$ & $\begin{array}{l}0.19^{\star \star} \\
0.21^{\star \star} \\
-0.03 \\
-0.05 \\
-0.06 \\
-0.00\end{array}$ & $\begin{array}{r}-0.01 \\
0.05 \\
0.24 \\
-0.05 \\
0.01 \\
0.00\end{array}$ & $\begin{array}{l}0.08^{\star \star} \\
0.11^{\star \star} \\
0.12 \\
0.01 \\
0.03 \\
-0.00\end{array}$ & $\begin{array}{l}0.14^{\star \star} \\
0.14^{\star \star} \\
-0.14 \\
-0.03 \\
-0.00 \\
-0.00\end{array}$ & $\begin{array}{c}-0.14^{\star \star} \\
-0.11^{\star \star} \\
0.19 \\
0.08 \\
-0.00 \\
0.00\end{array}$ & $\begin{array}{l}0.10^{\star *} \\
0.20^{\star *} \\
-0.34 \\
-0.05 \\
-0.14 \\
-0.00\end{array}$ & $\begin{array}{l}0.23^{\star \star} \\
0.33^{\star \star} \\
0.01 \\
-0.10 \\
-0.16 \\
-0.00\end{array}$ & $\begin{array}{l}0.13^{\star \star} \\
0.17^{\star \star} \\
0.07 \\
-0.16 \\
-0.10 \\
-0.00\end{array}$ \\
\hline \multicolumn{10}{|c|}{ Panel D. Regression Statistics } \\
\hline $\begin{array}{l}R^{2} \\
\text { No. of obs. }\end{array}$ & $\begin{array}{l}0.16 \\
3,651\end{array}$ & $\begin{array}{l}0.13 \\
3,651\end{array}$ & $\begin{array}{l}0.05 \\
3,651\end{array}$ & $\begin{array}{l}0.05 \\
3,651\end{array}$ & $\begin{array}{l}0.06 \\
3,651\end{array}$ & $\begin{array}{l}0.05 \\
3,651\end{array}$ & $\begin{array}{l}0.06 \\
3,651\end{array}$ & $\begin{array}{l}0.10 \\
3,651\end{array}$ & $\begin{array}{l}0.06 \\
3,651\end{array}$ \\
\hline \multicolumn{10}{|c|}{ Panel E. High Minus Low Regime } \\
\hline $\begin{array}{l}\mathrm{SP} \\
\mathrm{SP}_{t-1} \\
\mathrm{TN} \\
\mathrm{TN}_{t-1} \\
\mathrm{Z}_{t-1} \\
\alpha\end{array}$ & $\begin{array}{l}0.24^{\star \star} \\
0.35^{\star \star} \\
0.10 \\
-0.22 \\
-0.37^{\star \star} \\
-0.00\end{array}$ & $\begin{array}{l}0.17^{\star \star} \\
0.15^{\star \star} \\
-0.04 \\
-0.02 \\
-0.06 \\
-0.00\end{array}$ & $\begin{array}{c}0.08^{\star \star} \\
0.10^{\star} \\
0.01 \\
-0.17 \\
0.05 \\
0.00\end{array}$ & $\begin{array}{c}0.14^{\star \star} \\
0.13^{\star \star} \\
-0.06 \\
-0.08 \\
0.03 \\
-0.00\end{array}$ & $\begin{array}{l}0.17^{\star \star} \\
0.14^{\star \star} \\
-0.25 \\
-0.09 \\
-0.03 \\
-0.00\end{array}$ & $\begin{array}{c}-0.11^{* *} \\
-0.11^{\star *} \\
0.09 \\
-0.09 \\
-0.01 \\
0.00\end{array}$ & $\begin{array}{l}0.14^{\star \star} \\
0.18^{\star \star} \\
-0.48^{\star} \\
-0.12 \\
-0.19^{\star} \\
-0.00\end{array}$ & $\begin{array}{l}0.20^{\star \star} \\
0.28^{\star \star} \\
-0.00 \\
-0.17 \\
-0.19 \\
-0.00\end{array}$ & $\begin{array}{l}0.16^{\star \star} \\
0.12^{\star} \\
-0.06 \\
-0.30 \\
-0.15 \\
-0.00\end{array}$ \\
\hline
\end{tabular}

\section{Larger Set of Currencies}

Constructing the CT strategy from a larger base of 20 currencies (G20) instead of 10 currencies does not alter the conclusion. To show this, column 4 
of Table 2 reports results for a CT strategy based on the G10 and 10 additional currencies for 2003-2008. The sample starts in 2003 in order to guarantee high quality data and the existence of an active CT market. (It can be shown that the results for the G10 in the shorter sample period are very similar to those for the longer sample period.)

The results for the larger set of currencies are very much in line with those for the G10 currencies, and perhaps even stronger. In particular, the negative exposure to the bond market is stronger (and significant). The results for the G20 are also robust to the choice of stock index (see columns 5 and 6 of Table 2).

Accounting for the transaction costs decreases the CT performance by 1 percentage point per year but does not affect the slope coefficients, as in the G10 case. Although the trading costs are higher for these additional 10 currencies, there is less rebalancing, since some of the interest rate differentials are extremely persistent. Overall this leads to almost the same adjustment of the average performance as in the G10 case.

\section{E. Asset Pricing Analysis}

The regime-dependent risk exposures have important implications for the cross-sectional fit of the model. To illustrate this, we estimate a simplified model with the following specification: i) the factors $\left(f_{t}\right)$ are only contemporaneous variables, ii) SP and TN are expressed as excess returns over a risk-free U.S. interest rate, and iii) the parameters of the logistic function are fixed (at the values estimated from the CT return).

By these simplifications, the model becomes testable (sufficient number of test assets compared to factors) and is a linear factor model with the following factors:

$$
f_{t}=\left[\mathrm{SP}_{t}, \mathrm{TN}_{t}, G_{t-1} \times \mathrm{SP}_{t}, G_{t-1} \times \mathrm{TN}_{t}, G_{t-1}\right]
$$

Since some of the factors are not excess returns, the asset pricing implications are tested by studying whether the cross-sectional variation in average returns is explained by the $\beta$ s of the factors,

$$
\sum_{t=1}^{T} r_{t} / T=\beta^{\prime} \lambda
$$

where $\lambda$ is a vector of factor risk premia. The model is estimated by GMM, where the 1 st set of moment conditions effectively estimates the betas (and an intercept) by regressing each currency return on the factors (time-series regressions), and the 2nd set of moment conditions estimates the factor risk premia by a cross-sectional regression. We discipline the exercise by using the fact that the SP and TN are excess returns: These factors are included in the vector of test assets (together with the currencies) and formulate the moment conditions so that the factor risk premia for these 2 factors are just their average returns.

Figure 4 compares the results from using just SP and TN (Graph A, a 2-factor model) with those from using all 5 factors (Graph B) in equation (7) for the G10 sample. While the 2-factor model explains virtually nothing of the cross-sectional variation of the currency returns, the 5-factor model is much more successful. 
For instance, the low return on JPY is well explained, mostly by the negative exposure to equities in the high volatility state. Similarly, the pricing error (the vertical distance to the $45^{\circ}$ line) for the CT strategy is substantially smaller in the 5-factor model, although it is not 0 . Because of the few degrees of freedom, the power of formal tests of the model is low.

\section{FIGURE 4}

\section{Cross-Sectional Fit of Asset Pricing Model (G10 Top, G20 Bottom)}

Figure 4 shows scatter plots of the actual average return (vertical axis) against the fitted average return (horizontal axis), $\beta^{\prime} \lambda$. Graph A (Graph B) is for the G10 currencies (1995-2008), using a 2- (5-) factor model. Graphs C and D are similar, but for the G20 currencies (2003-2008).
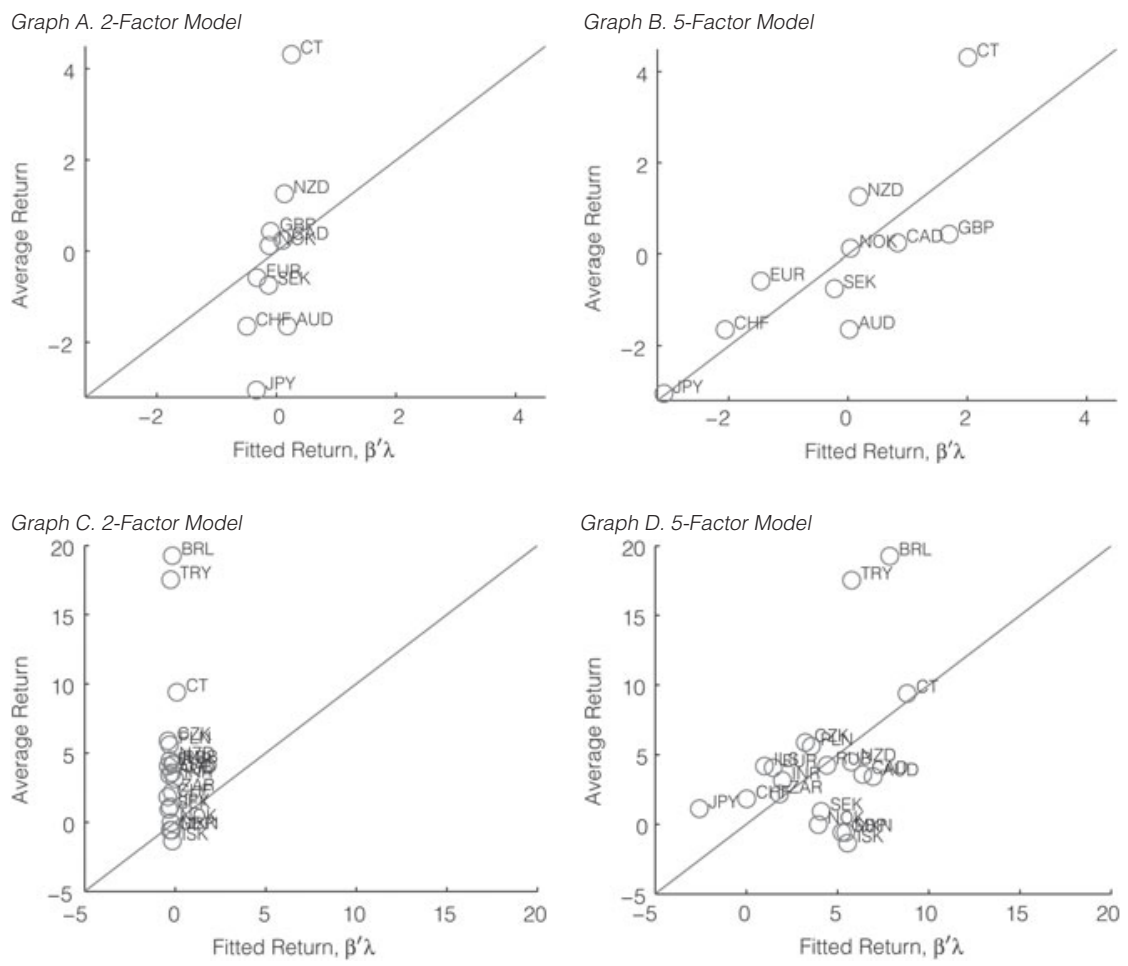

Graphs C and D of Figure 4 show the asset pricing implication for the 20 currencies and the corresponding CT strategy. As before, the 2-factor model explains almost nothing of the cross-sectional variation of average returns, while the 5 -factor model works much better. In contrast to the previous case, the formal test of the overidentifying restrictions has enough degrees of freedom to discriminate between the models: The 2-factor model is rejected at the $2 \%$ significance level, while the 5-factor model cannot be rejected even at the $20 \%$ significant level. The pricing error of the CT strategy is virtually 0 in the 5-factor model (but almost $10 \%$ in the 2-factor model).

Overall, this gives considerable support for a model with regime-dependent risk exposures. 


\section{F. Other Regime Variables}

So far, we have related the regime mechanism to a measure of risk on exchange rate markets, the $\mathrm{FXV}_{t}$. Here, we extend our analysis to more general proxies of global risk or risk aversion (the VIX, as used by Lustig et al. (2008) and Menkhoff et al. (2011)), to funding liquidity (the TED, as in Brunnermeier et al. (2009)) as well as to market liquidity (the JPY/USD bid-ask spread, which is a measure of transaction cost due to market illiquidity (Roll (1984)) and asymmetric information (Glosten and Milgrom (1985))).

Table 4 presents the smooth transition regressions for the CT strategy for the sample 1997-2008 for different choices of the regime variable. The sample starts in 1997 (instead of 1995) due to limited data availability for some of the new regime variables.

TABLE 4

Smooth Transition Regression with Different Regime Variables

Table 4 presents the parameter estimates arising from estimating the logistic smooth transition regression model on carry trade excess returns (1997-2008). The regime variables are 1-day lagged values of the: FX volatility (FXV) (column 1), TED spread (column 2), volatility index (VIX) (column 3), and bid-ask spread (column 4). Column 5 includes all 4 regime variables jointly. Based upon Newey and West (1987) standard errors, ${ }^{*}$ and ${ }^{* \star}$ indicate that the parameter is significantly different from 0 at the $5 \%$ and $1 \%$ levels, respectively.

\begin{tabular}{|c|c|c|c|c|c|}
\hline \multirow[b]{2}{*}{$\underline{\text { Coefficients }}$} & \multicolumn{5}{|c|}{ Regime Variable } \\
\hline & FXV & TED & VIX & $\begin{array}{l}\text { Bid-Ask } \\
\text { Spread }\end{array}$ & All \\
\hline \multicolumn{6}{|c|}{ Panel A. Regime Function } \\
\hline $\begin{array}{l}\gamma_{\mathrm{FXV}} \\
\gamma_{\mathrm{TED}} \\
\gamma_{\mathrm{VIX}} \\
\gamma_{\mathrm{BA}} \\
c\end{array}$ & $2.83^{\star *}$ & $1.31^{\star \star}$ & $\begin{array}{l}11.84^{\star \star} \\
2.35^{\star \star}\end{array}$ & $\begin{array}{l}2.38^{\star \star} \\
1.81^{\star \star}\end{array}$ & $\begin{array}{l}1.68^{*} \\
1.68^{\star \star} \\
0.39 \\
-0.22 \\
0.81^{\star \star}\end{array}$ \\
\hline \multicolumn{6}{|c|}{$\underline{\text { Panel B. Low Regime }}$} \\
\hline $\begin{array}{l}\mathrm{SP} \\
\mathrm{SP}_{t-1} \\
\mathrm{TN} \\
\mathrm{TN}_{t-1} \\
\mathrm{z}_{t-1} \\
\alpha\end{array}$ & $\begin{array}{l}0.03^{*} \\
0.04^{* *} \\
0.00 \\
-0.03 \\
0.02 \\
0.00^{\star *}\end{array}$ & $\begin{array}{l}0.02 \\
0.04^{\star \star} \\
0.05 \\
-0.02 \\
0.04 \\
0.00^{\star}\end{array}$ & $\begin{array}{l}0.05^{\star \star} \\
0.05^{\star \star} \\
-0.04^{\star} \\
-0.05^{\star} \\
-0.00 \\
0.00^{\star \star}\end{array}$ & $\begin{array}{c}0.04^{\star \star} \\
0.06^{\star \star} \\
-0.03 \\
-0.03 \\
-0.02 \\
0.00^{\star}\end{array}$ & $\begin{array}{l}0.02 \\
0.03^{\star \star} \\
0.04 \\
-0.02 \\
0.03 \\
0.00^{\star \star}\end{array}$ \\
\hline \multicolumn{6}{|c|}{$\underline{\text { Panel C. High Regime }}$} \\
\hline $\begin{array}{l}\mathrm{SP} \\
\mathrm{SP}_{t-1} \\
\mathrm{TN} \\
\mathrm{TN}_{t-1} \\
z_{t-1} \\
\alpha\end{array}$ & $\begin{array}{l}0.20^{\star *} \\
0.25^{\star *} \\
-0.25 \\
-0.09 \\
-0.18^{\star} \\
0.00^{\star}\end{array}$ & $\begin{array}{l}0.19^{\star \star} \\
0.24^{\star \star} \\
-0.35 \\
-0.17 \\
-0.20^{\star} \\
-0.00^{\star}\end{array}$ & $\begin{array}{l}0.19^{\star \star} \\
0.26^{\star \star} \\
-0.17 \\
-0.10 \\
-0.23^{\star} \\
-0.00^{\star \star}\end{array}$ & $\begin{array}{l}0.20^{\star \star} \\
0.23^{\star \star} \\
-0.15 \\
-0.30 \\
-0.11 \\
-0.00\end{array}$ & $\begin{array}{l}0.19^{\text {** }} \\
0.24^{\star *} \\
-0.30 \\
-0.13 \\
-0.18^{*} \\
-0.00^{*}\end{array}$ \\
\hline \multicolumn{6}{|c|}{$\underline{\text { Panel D. Regression Statistics }}$} \\
\hline $\begin{array}{l}R^{2} \\
\text { No. of obs. }\end{array}$ & $\begin{array}{l}0.21 \\
3,132\end{array}$ & $\begin{array}{l}0.22 \\
3,132\end{array}$ & $\begin{array}{l}0.20 \\
3,132\end{array}$ & $\begin{array}{l}0.18 \\
3,132\end{array}$ & $\begin{array}{l}0.23 \\
3,132\end{array}$ \\
\hline \multicolumn{6}{|c|}{ Panel E. High Minus Low Regime } \\
\hline $\begin{array}{l}\mathrm{SP} \\
\mathrm{SP}_{t-1} \\
\mathrm{TN} \\
\mathrm{TN}_{t-1} \\
z_{t-1} \\
\alpha\end{array}$ & $\begin{array}{l}0.17^{\star \star} \\
0.21^{\star \star} \\
-0.25 \\
-0.06 \\
0.20^{\star} \\
0.00^{\star}\end{array}$ & $\begin{array}{l}0.17^{\star \star} \\
0.21^{\star \star} \\
-0.40^{\star} \\
-0.15 \\
-0.23^{\star} \\
-0.00^{\star}\end{array}$ & $\begin{array}{l}0.14^{\star \star} \\
0.20^{\star \star} \\
-0.13 \\
-0.05 \\
-0.23^{\star} \\
-0.00^{\star \star}\end{array}$ & $\begin{array}{l}0.16^{\star \star} \\
0.17^{\star \star} \\
-0.12 \\
-0.27 \\
-0.09 \\
-0.00^{\star}\end{array}$ & $\begin{array}{l}0.17^{\star \star} \\
0.21^{\star \star} \\
-0.34 \\
-0.11 \\
-0.21^{\star} \\
-0.00^{\star \star}\end{array}$ \\
\hline
\end{tabular}

The correlations between these different regime variables are reasonably high (0.4-0.75), suggesting a well-expected covariation between risk and 
illiquidity (of any nature). Not surprisingly, the different regime variables generate fairly similar results for the time variation in risk exposure.

However, a direct horse race favors the FX volatility and the TED over VIX and the bid-ask spread. The last column of Table 4 reports results from a regression where we use all 4 state variables simultaneously. Both the FXV and the TED are significant, while the VIX and bid-ask spread are not. (In this regression the state regime variables are rotated to be uncorrelated, but we obtain a similar result with the original variables.)

These findings suggest that FX market volatility and funding liquidity might be more important than risk measures related to equity markets (VIX) and direct measures of FX (interdealer) market liquidity (bid-ask spread). This is somewhat similar to the findings on the equity market by Bandi, Moise, and Russell (2008).

\section{G. Further Robustness Analysis}

\section{Longer Sample Period}

It is of considerable interest to see if the properties of CT documented previously (on 1995-2008 and 2003-2008 data) also hold for earlier periods, especially during periods of marked FX market turmoil. We therefore also study the 1976-2008 sample for a reduced currency base (7 currencies).

We define a new FX volatility variable (since data on the FX options are not available before 1995), namely a 15-day moving average of the 1 st principal component of the absolute value of the FX daily returns (see Taylor (1986)). This new FX volatility variable is backward looking and does not necessarily represent the beliefs of market participants, but it is still a reasonable approximation. For instance, over the 1995-2008 sample the correlation with the option-based measure is 0.85 .

For this longer sample period most coefficients are numerically small (cf. Burnside et al. (2011), who find no relation between CT strategies and an equity factor for the same time period). However, the exposure to equities in the high volatility state is as strong as in the shorter sample period $(0.18$ for the contemporaneous coefficient and 0.21 for the lagged coefficient). The details of these findings are available from the authors.

Overall, it seems as if the time-varying exposure to equities has been an important feature during both earlier periods of FX market turbulence as well as during more recent episodes. This suggests that our findings cannot be driven solely by the current financial crisis.

\section{Effects of Order Flow}

In the market microstructure literature, the order flow is often thought of as representing the net demand pressure (Evans and Lyons (2002)). To investigate the importance of order flow, we estimate the logistic smooth transition regressions for the JPY/USD for the sample 1997-2008, with and without adding order flow as an explanatory variable. Order flow data are constructed from firm quotes obtained by the tick-by-tick data of EBS. The coefficient related to the order flow is significantly positive, so there is a significant price impact, meaning that demand pressure is associated with currency appreciation, as expected. More importantly 
for our paper, however, is the fact that the inclusion of the order flow does not materially change the betas on the equity and bond markets. The details of these findings are available from the authors.

This finding suggests that our previous conclusions on the time-varying risk exposure are not sensitive to the inclusion/exclusion of order flow.

\section{Conclusion}

This paper studies the risk exposure of CT returns by estimating factor models on daily data from 1995 to 2008. The risk factors are traditional (equity and bond returns), but the risk exposures are allowed to depend on proxies for volatility and (market and funding) liquidity.

The results from CT strategies based on the G10 currencies show that the risk exposures of the $\mathrm{CT}$ returns are highly regime dependent: The beta related to the stock market is positive in normal times, and much more so during turbulent times. In addition, the returns are more predictable (mean reverting) during turmoil and have a direct exposure to a volatility factor. The results also hold for individual currencies: Typical investment currencies have a positive exposure to equities, and this exposure is much larger during periods of FX market turmoil, while typical funding currencies are the mirror image. The results are robust to the application of a larger set of currencies, including emerging market currencies, longer sample periods, other definitions of stock market returns, net of transaction costs, and controlling for order flow.

The economic importance of the results is significant. For instance, the (abysmal) performance of CT strategies during times of high (extreme) market volatility is $1 / 3$ driven by exposure to traditional risk factors (equity and bond returns) and $2 / 3$ driven by exposure to the volatility factor itself. Moreover, the regime-dependent factor model assigns a very small pricing error to the CT strategy, in stark contrast to a traditional factor model, which suggests a zero risk premium for the strategy.

We test several variables in order to determine which factors govern the regime dependency of the systematic risk inherent to the CT strategies. We find that FX market volatility and funding liquidity (the TED spread) are more relevant than measures of equity market volatility and risk aversion (VIX) or the FX market liquidity (bid-ask spreads).

Our findings provide further evidence on the recent research showing that financial markets are regime dependent with stronger comovements during financial crises, and that volatility and liquidity have important direct effects on asset returns. Our results also indicate that CTs look less attractive once correctly priced by means of regime-dependent models, suggesting a partial resolution of the UIP puzzle.

\section{References}

Acharya, V. V., and L. H. Pedersen. "Asset Pricing with Liquidity Risk." Journal of Financial Economics, 77 (2005), 375-410.

Ang, A.; R. J. Hodrick; Y. Xing; and X. Zhang. "The Cross-Section of Volatility and Expected Returns." Journal of Finance, 61 (2006), 259-299. 
Bacchetta, P., and E. van Wincoop. "Can Information Heterogeneity Explain the Exchange Rate Determination Puzzle?” American Economic Review, 96 (2006), 552-576.

Bandi, F. M.; C. E. Moise; and J. R. Russell. "The Joint Pricing of Volatility and Liquidity.” Working Paper, University of Chicago (2008).

Bansal R., and M. Dahlquist."The Forward Premium Puzzle: Different Tales from Developed and Emerging Economies.” Journal of International Economics, 51 (2000), 115-144.

Bekaert, G., and S. F. Gray. "Target Zones and Exchange Rates: An Empirical Investigation.” Journal of International Economics, 45 (1998), 1-35.

Bhansali, V. "Volatility and the Carry Trade." Journal of Fixed Income, 17 (2007), 72-84.

Brunnermeier, M. K.; S. Nagel; and L. H. Pedersen. "Carry Trades and Currency Crashes." NBER Macroeconomics Annual 2008, 23 (2009), 313-347.

Burnside, C.; M. Eichenbaum; I. Kleshchelski; and S. Rebelo. "Do Peso Problems Explain the Returns to the Carry Trade?" Review of Financial Studies, 24 (2011), 853-891.

Burnside, C.; M. Eichenbaum; and S. Rebelo. "The Returns to Currency Speculation in Emerging Markets.” American Economic Review, 97 (2007), 333-338.

Corsetti, G.; M. Pericoli; and M. Sbracia. “'Some Contagion, Some Interdependence': More Pitfalls in Tests of Financial Contagion." Journal of International Money and Finance, 24 (2005), 11771199.

Embrechts, P.; A. J. McNeil; and D. Straumann. "Correlation and Dependence in Risk Management: Properties and Pitfalls." In Risk Management: Value at Risk and Beyond, M. A. H. Dempster, ed. Cambridge, UK: Cambridge University Press (2002).

Evans, M. D. D., and R. K. Lyons. "Order Flow and Exchange Rate Dynamics." Journal of Political Economy, 110 (2002), 170-180.

Fama, E. F. "Forward and Spot Exchange Rates." Journal of Monetary Economics, 14 (1984), 319-338.

Farhi, E., and X. Gabaix. "Rare Disasters and Exchange Rates.” Working Paper, Harvard University and New York University (2008).

Forbes, K. J., and R. Rigobon. "No Contagion, Only Interdependence: Measuring Stock Market Comovements.” Journal of Finance, 57 (2002), 2223-2261.

Gagnon, J. E., and A. P. Chaboud. "What Can the Data Tell Us about Carry Trades in Japanese Yen?" International Finance Discussion Paper 899, Federal Reserve Bank (2007).

Glosten, L. R., and P. R. Milgrom. "Bid, Ask and Transaction Prices in a Specialist Market with Heterogeneously Informed Traders.” Journal of Financial Economics, 14 (1985), 71-100.

Gyntelberg, J., and E. M. Remolona. "Risk in Carry Trade: A Look at Target Currencies in Asia and the Pacific.” BIS Quarterly Review (2007), 73-82.

Hattori, M., and H. S. Shin. "The Broad Yen Carry Trade.” Working Paper, Bank of Japan (2007).

Ichiue, H., and K. Koyama. "Regime Switches in Exchange Rate Volatility and Uncovered Interest Parity.” Working Paper, Bank of Japan (2008).

Lustig, H.; N. Roussanov; and A. Verdelhan. "Common Risk Factors in Currency Markets." Working Paper 14082, NBER (2008).

Lyons, R. K. The Microstructure Approach to Exchange Rates. Cambridge, MA: MIT Press (2001).

Mark, N. C. "Time-Varying Betas and Risk Premia in the Pricing of Forward Exchange Contracts." Journal of Financial Economics, 22 (1988), 335-354.

McCurdy, T. H., and I. G. Morgan. "Tests for a Systematic Risk Component in Deviations from Uncovered Interest Rate Parity.” Review of Economic Studies, 58 (1991), 587-602.

Menkhoff, L.; L. Sarno; M. Schmeling; and A. Schrimpf. "Carry Trades and Global Foreign Exchange Volatility." Journal of Finance, forthcoming (2011).

Newey, W. K., and K. D. West. "A Simple, Positive Semi-Definite, Heteroskedasticity and Autocorrelation Consistent Covariance Matrix.” Econometrica, 55 (1987), 703-708.

Plantin, G., and H. S. Shin. "Carry Trades and Speculative Dynamics." Working Paper, London Business School and Princeton University (2008).

Ranaldo, A., and P. Söderlind. "Safe Haven Currencies.” Review of Finance, 14 (2010), 385-407.

Roll, R. "A Simple Implicit Measure of the Effective Bid-Ask Spread in an Efficient Market." Journal of Finance, 39 (1984), 1127-1139.

Sarno, L.; G. Valente; and H. Leon. "Nonlinearity in Deviations from Uncovered Interest Parity: An Explanation of the Forward Bias Puzzle." Review of Finance, 10 (2006), 443-482.

Taylor, S. Modeling Financial Time Series. New York, NY: Wiley (1986).

van Dijk, D.; T. Teräsvirta; and P. H. Franses. "Smooth Transition Autoregressive Models-A Survey of Recent Developments." Econometric Reviews, 21 (2002), 1-47. 